\title{
Effects of two different doses of carbohydrate ingestion on taekwondo- related performance during a simulated tournament
}

Alireza Naderi ${ }^{1 *}$ D, Mohammad Hossein Samanipour ${ }^{2}$, Amir Sarshin $^{3}$, Scott C. Forbes ${ }^{4}$, Majid S. Koozehchian ${ }^{5}$, Emerson Franchini ${ }^{6}$, Reid Reale ${ }^{7}$, Erfan Berjisian ${ }^{8}$, Erick P. de Oliveira ${ }^{9}$, Hossein Miraftabi $^{8}$,

Maryam Safari Sharafshadeh ${ }^{10}$ and Sajjad Rezaei ${ }^{11}$

\begin{abstract}
Background: Carbohydrate $(\mathrm{CHO})$ ingestion enhances exercise performance; however, the efficacy of $\mathrm{CHO}$ intake on repeated bouts of exercise simulating a taekwondo tournament is unknown. Therefore, the purpose was to compare the effects of two different doses of $\mathrm{CHO}$ on a sports-specific kicking test during a simulated taekwondo tournament compared to placebo (PLA).

Methods: In a double-blind, randomized-placebo controlled, cross-over trial, eleven junior male professional taekwondo athletes (age: $16 \pm 0.8$ years, body mass: $55.3 \pm 7.3 \mathrm{~kg}$ ) ingested one of three solutions: (i) high dose (C45): $45 \mathrm{~g}$ of $\mathrm{CHO}\left(60 \mathrm{~g} \cdot \mathrm{h}^{-1}\right)$, (ii) low dose (C22.5): $22.5 \mathrm{~g}$ of $\mathrm{CHO}\left(30 \mathrm{~g} \cdot \mathrm{h}^{-1}\right.$; both solutions containing 2:1 glucose: fructose), or a PLA immediately following each kicking test. The kicking test was repeated 5 times, separated by 45 mins of rest, simulating a typical taekwondo competition day. Ratings of perceived exertion (RPE) and gastrointestinal discomfort (Gl) scores were collected immediately after, and blood glucose before each test.
\end{abstract}

Results: The results revealed that C45 and C22.5 did not improve total, successful, or percentage of successful kicks compared to PLA ( $p>0.05)$. Blood glucose was significantly higher following both $\mathrm{CHO}$ conditions compared with PLA across all five tests $(p<0.05)$. There were no differences between treatments or across tests for RPE $(p>0.05)$.

Conclusion: $\mathrm{CHO}$ intake, independent of the dose, did not alter taekwondo kick performance during a simulated taekwondo tournament.

Keywords: High-intensity intermittent Exercice, Rating of perceived exertion, Blood glucose, Combat sports

\footnotetext{
* Correspondence: Naderi_a@yahoo.com

'Department of Sport Physiology, Boroujerd Branch, Islamic Azad University, Boroujerd, Iran

Full list of author information is available at the end of the article
}

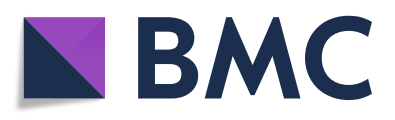

(- The Author(s). 2021 Open Access This article is licensed under a Creative Commons Attribution 4.0 International License, which permits use, sharing, adaptation, distribution and reproduction in any medium or format, as long as you give appropriate credit to the original author(s) and the source, provide a link to the Creative Commons licence, and indicate if changes were made. The images or other third party material in this article are included in the article's Creative Commons licence, unless indicated otherwise in a credit line to the material. If material is not included in the article's Creative Commons licence and your intended use is not permitted by statutory regulation or exceeds the permitted use, you will need to obtain permission directly from the copyright holder. To view a copy of this licence, visit http://creativecommons.org/licenses/by/4.0/. The Creative Commons Public Domain Dedication waiver (http://creativecommons.org/publicdomain/zero/1.0/) applies to the data made available in this article, unless otherwise stated in a credit line to the data. 


\section{Introduction}

Taekwondo is one of the most popular weight-classified striking combat sports that has progressed into modernday Olympics Games [1]. Taekwondo competition matches include three 2-min rounds, with 1 min rest between each round [2]. This combat sport is characterized by high-intensity intermittent activity with 0.7 to 1.7 -s attacks that include 1-3 kicks and punches, which are interspersed with $2-8 \mathrm{~s}$ of low-intensity action composed by step or pause [2]. Each athlete in a tournament typically fights 3-7 matches across 1-2 days, depending on their successful advancement throughout the tournament [3]. One of the critical physiological challenges of a taekwondo (and other combat sport) athlete is the short recovery time between each match, which is typically between $30 \mathrm{~min}$ and $2 \mathrm{~h}$ during a tournament $[4,5]$. As such, nutritional strategies that accelerate acute recovery between matches may potentially improve subsequent performance $[4,6,7]$.

Although oxidative metabolism is the primary energy source during a taekwondo match, increased non-oxidative (i.e., anaerobic) contribution is involved during the kicking and punching actions, and is required to maintain lower-limb power output [2]. Carbohydrate $(\mathrm{CHO})$ in the form of muscle and liver glycogen is the main finite fuel to regenerate ATP via both anaerobic and oxidative metabolic pathways [8]. Lower blood glucose and $\mathrm{CHO}$ oxidation rates along with glycogen storage depletion during prolonged exercise contribute to fatigue [9], which may impair exercise performance $[10,11]$. $\mathrm{CHO}$ ingestion before and/or during exercise in a dose/type-dependent manner can prevent hypoglycemia and sustain exercise performance in both continuous and intermittent high-intensity prolonged exercises [12-15]. However, CHO's ergogenic benefits depend on the duration, intensity, and type of exercise [16]. CHO (30-90 g.h $\left.{ }^{-1}\right)$ containing a 2:1 ratio of glucose:fructose are recommended for exercise lasting 1-3 h [17], whereas rinsing ones mouth with a $\mathrm{CHO}$ solution for $10 \mathrm{~s}$ without ingestion may improve exercise performance at times when substrate availability is not typically performance limiting (e.g., in efforts lasting $<30 \mathrm{~min}$ ) via central nervous system effects [17]. Further, CHO ingestion during recovery from intense exercise is critical to replenish glycogen storage and may aid subsequent exercise performance in events with short recovery times $(<4 \mathrm{~h})$ [18]. Recently, McCarthy et al. 2020 showed that $1.2 \mathrm{~g} \mathrm{CHO} \cdot \mathrm{kg}^{-1}$ ingested during 2 hours of recovery between repeated bouts of interval endurance exercise improved subsequent exercise performance, reduced ratings of perceived exertion (RPE) and fatigue by $35 \%$ compared to placebo [7]. The aforementioned findings highlight the impact of $\mathrm{CHO}$ on acute performance and suggest improvements in subsequent exercise performance in a variety of contexts when short recovery periods between bouts exist; however, the role of $\mathrm{CHO}$ ingestion on multiple daily matches such as a taekwondo tournament is yet to be investigated. In taekwondo athletes, greater cortisol [19] along with higher blood lactate, increases reaction time and reduces kick impact in a fatigued state [20], which may be related to glycogen depletion [21]. However, counterintuitively, no ergogenic effect of $\mathrm{CHO}$ mouth rinsing was found when athletes were tested six times during four weeks of Taekwondo Anaerobic Intermittent Kick Tests (TAIKT) in 27 taekwondo players in both fasted or fed states [22]. Presently, there is a paucity of research that has examined the role of $\mathrm{CHO}$ ingestion on taekwondo performance during a simulated tournament, with athletes competing in multiple matches across a day.

Thus, this study aimed to compare the effects of two different dosages of $\mathrm{CHO}$ drinks, equating to 30 and 60 $\mathrm{g} \cdot \mathrm{h}^{-1}$ compared to placebo, on: total kicks, successful kicks and successful kicks percentage, blood glucose (BG), and RPE following five sport-specific kicking tests repeated every $45 \mathrm{~min}$, designed to simulate a taekwondo tournament. We hypothesized that $\mathrm{CHO}$ ingestion would augment total and successful kicks by maintaining BG across multiple tests, in a dose response fashion, compared to placebo (PLA).

\section{Methods}

\section{Participant}

Twelve junior male professional taekwondo black belt athletes (age: $16 \pm 0.8$ years, body mass: $55.3 \pm 7.3 \mathrm{~kg}$, height: $177.6 \pm 1.9 \mathrm{~cm}$, competition experience: $5.8 \pm 1.0$ years) were recruited to participate in this study. The inclusion criteria of the study included having more than 5 years' experience in taekwondo competitions, and training more than 5 hours during the week for 3 months prior to the initiation of the study. Participants were excluded from the study if they had skeletal muscle injuries or reported consuming any nutritional ergogenic aids within 3 months of the start of the study. Participants were informed about the nature and potential risks and benefits of the experimental protocols. Participants were not cutting weight during the study. One participant was injured during the test and was removed from the study. The study was conducted following the Declaration of Helsinki and approved by Islamic Azad University of Boroujerd, Iran.

\section{Design}

In a randomized, double-blind, cross-over placebocontrolled manner, participants engaged in five sessions, including a screening visit, familiarization, and three 
experimental trials where participants ingested drinks with different contents including two doses of $\mathrm{CHO}$ and placebo, each experimental condition was separated by at least 5 days. The supplementation protocol followed a double-blind manner by an independent researcher at each experimental trial. At the familiarization session, each participant completed the test protocol. Participants repeated the tests to become familiar with the audio signals. An experienced taekwondo coach provided technique corrections during the simulated taekwondo effort test (STET) to ensure proper form. All of the trials were conducted on the same day of the week and at the same time controlling for alterations in circadian rhythm. The temperature and relative humidity were controlled across the tests $\left(\sim 25^{\circ} \mathrm{C}, \sim 70 \%\right.$ relative humidity). Participants were asked to record their diet and activity pattern 2 days before the familiarization session and to replicate it during the three experimental trials. They were also instructed to refrain from consuming alcohol and caffeine, and to avoid strenuous training 24 $\mathrm{h}$ prior to each test. BG was obtained before each test using a glucometer (Maximed ExiChek II; TD-4224A, Taiwan) by lancing a warmed fingertip (Same care; ExiChek, TD-4224, Taiwan).

Body mass was monitored before and after each test using a calibrated scale (AFW-120 K; Seca LTD, Birmingham, United Kingdom) to investigate a possible hypohydration, which is known to decrease exercise performance [23]. A validated gastrointestinal questionnaire was also used to assess gastrointestinal (GI) distress immediately after each test [24]. A schematic of the study design is presented in Fig. 1.

\section{Experimental trials}

Participants arrived at the gym from 7:00-7:30 a.m. each trial day and consumed a standardized breakfast consisting of $\sim 1 \mathrm{~g} \cdot \mathrm{kg}^{-1} \mathrm{CHO}$ (white bread) and $\sim 20 \mathrm{~g}$ protein
( 6 boiled egg white). The test began 3 hours after consuming breakfast. Fifteen minutes before the first test, all participants performed a standardized warm-up that included basic kicks with a moderate rhythm and dynamic stretching. Participants were divided into four groups of three taekwondo athletes. They started to perform the STET, modified based on the Frequency Speed of Kick Test [25]. This test was divided into 3 rounds with $1 \mathrm{~min}$ rest between each round (each round lasting $200 \mathrm{~s}$ ). An audio signal was used to indicate when the participants were required to start and stop kicking the 'Hugo' electronic dummy (HTS; Hooshmand Techno system Co, Iran) which was connected to a computer to collect data electronically automatically. Each test was repeated 5 times, separated by a $45 \mathrm{~min}$ rest [4] to simulate a taekwondo tournament competition day. During the STET, the stationary roundhouse (bandal-tchagui) kick, the most used taekwondo technique [25] was used. After each round, both total and successful kick number were recorded. Successful kicks were detected and recorded by an electronic foot sensor and transferred to a computer. STET data were collected using an electronic body protector (Hts \& Hooshmand Techno Stem, Iran) located on the training dummy. Minimum impact thresholds were determined based on BM, age, and sex. If the kicking force was identified lower than the minimum impact threshold, the kick was not counted as a successful kick. After each test, RPE was recorded using the 6-20 Borg scale [26]. Verbal encouragement was given to all participants during the test.

\section{Carbohydrate beverage}

In order to ensure blinding of all researchers involved in data collection during the trials, $\mathrm{CHO}$ beverages were prepared by an independent researcher based on 30 $\mathrm{g} \cdot \mathrm{h}^{-1}$ or $60 \mathrm{~g} \cdot \mathrm{h}^{-1}$ with glucose and fructose at a ratio of $2: 1[9,17]$. As 45 min rest intervals were applied between

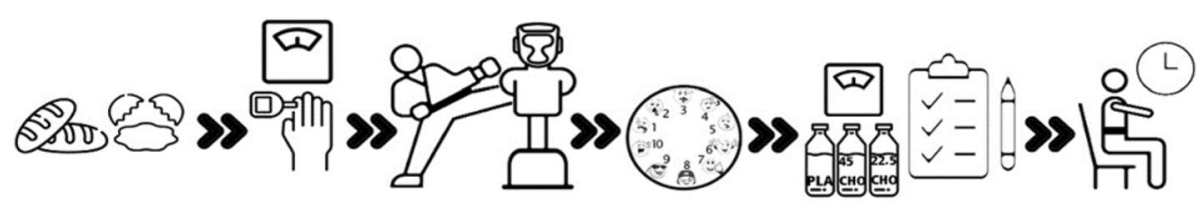

1.

Breakfast

the test
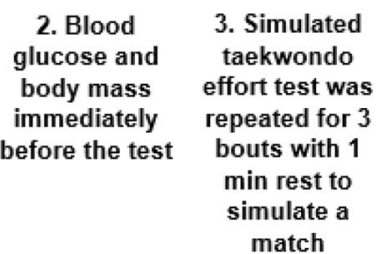

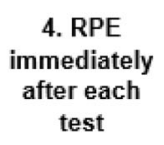

4. RPE immediately after each test 5. Body mass, GI discomfort questionnaire, $\mathrm{CHO}$ or PLA ingested

Steps 2 -5 repeated for a total 5 times with $\mathbf{4 5}$ min rest after each test

Fig. 1 Schematic representation of the study procedures with 5 test repetitions. $\mathrm{CHO}=$ carbohydrate; $\mathrm{Gl}$ = gastrointestinal; PLA = placebo 
each test, $600 \mathrm{~mL}$ solutions were prepared containing either $45 \mathrm{~g}$ of $\mathrm{CHO}\left(60 \mathrm{~g} \cdot \mathrm{h}^{-1}\right)$ including $30 \mathrm{~g}$ glucose (Roquette Industries Co., France) plus $15 \mathrm{~g}$ fructose (Hamburg fructose Industries Co., Germany) with 7.5\% concentration or $22.5 \mathrm{~g}\left(30 \mathrm{~g} \cdot \mathrm{h}^{-1}\right) \mathrm{CHO}$ including $15 \mathrm{~g}$ glucose $+7.5 \mathrm{~g}$ fructose and $1.1 \mathrm{~g}$ sweetener powder $(\mathrm{Su}-$ cralose E955; Kamvar, Isfahan Chocolate co., Iran) with $3.5 \%$ concentration and placebo beverage contained $2.2 \mathrm{~g}$ sweetener powder. Three drops of coconut flavor were added to each beverage to match the taste of all beverages. Each participant was instructed to ingest their respective beverage within $5 \mathrm{~min}$ after each test (tests 1 to 4), since the $\mathrm{CHO}$ ingestion timing pattern can influence exercise performance [27].

\section{Statistical analysis}

Values are presented as means \pm standard deviations. Normality was confirmed by using the Shapiro-Wilk test. A two-way analysis of variance with repeated measures were applied to explore the effect of different treatments (high and low CHO and PLA) and tests (5 tests over the competition day) on total kicks, total successful kicks, successful kick percentage (successful kicks/total kicks * 100), BG, and RPE. A three-way repeated measures ANOVA was applied to analyze body mass before and after each test and in each treatment. Bonferroni post hoc and within-subject $95 \%$ confidence interval (CI) error bars [28] were determined if appropriate. Partial eta-squared was used to indicate the magnitude of the differences. The interpretation of the effect size is based on the recommendations by Cohen: $0.01=$ small effect size, $0.06=$ moderate effect size, and $0.14=$ large effect size [29]. All calculations were performed using SPSS version 24 (IBM North America, New York, NY, USA) and the probability level for statistical significance was pre-set at $P \leq 0.05$.

\section{Results}

\section{Total kicks}

Figure 2 presents total kicks in each test and bouts during three treatments. For total kicks, treatment-by-test interaction $\left(\mathrm{F}_{8,80}=1.126, P=0.355, \eta_{P}^{2}=0.101\right)$ and main effect of treatment $\left(\mathrm{F}_{2,20}=2.332, P=0.123, \eta_{P}^{2}=0.189\right)$ were not significant. However, the main effect of test was significant $\left(\mathrm{F} 4,40=3.698, P=0.012, \eta_{P}^{2}=0.269\right)$, that is total kicks decreased from test one to five, as shown in Fig. 2.

\section{Total successful kicks}

Figure 3 shows the total successful kicks in each test and bouts during the three treatments. For total successful kicks, there were no significant treatment-by-test interaction $\left(\mathrm{F}_{8,80}=1.149, P=0.340, \eta_{P}^{2}=0.103\right)$ or main effect of treatment $\left(\mathrm{F}_{2,20}=2.033, P=0.157, \eta_{P}^{2}=0.169\right)$. However, the main effect of test was significant $\left(F_{4,40}=3.836\right.$, $\left.P=0.010, \eta_{P}^{2}=0.277\right)$, with total successful kicks decreasing from test one to five.

\section{Successful kick percentage}

Treatment-by-test interaction $\left(\mathrm{F}_{8,80}=1.401, P=0.209, \eta_{P}^{2}\right.$ $=0.123)$, main effect of treatment $\left(F_{2,20}=2.927, P=\right.$ $0.077, \eta_{P}^{2}=0.226$ ), and main effect of test were not sig-

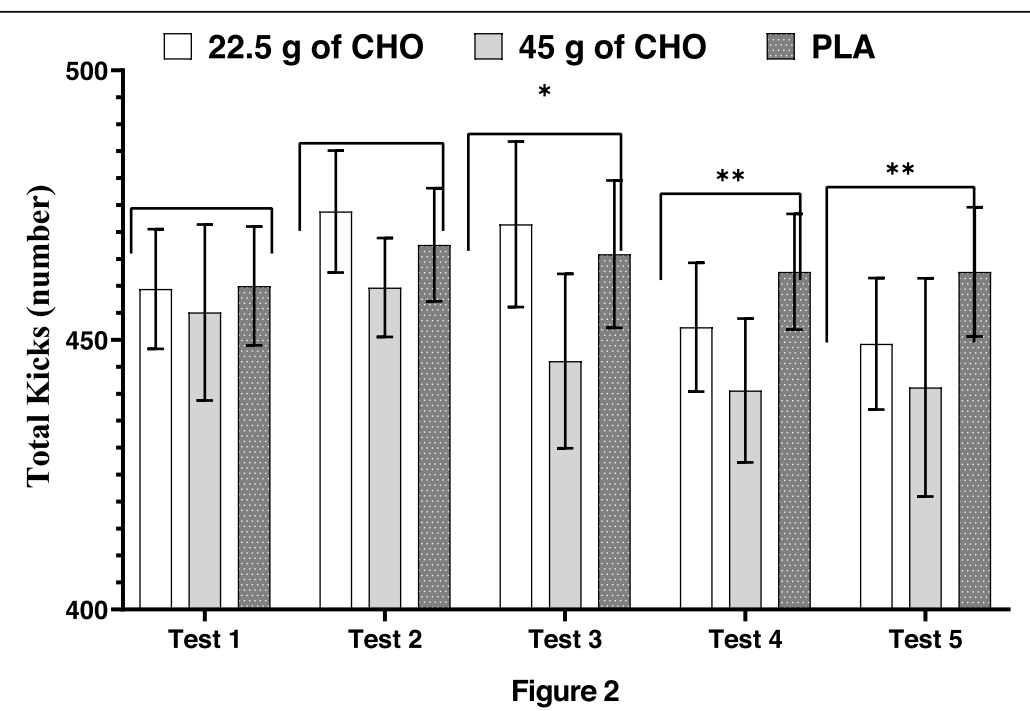

Fig. 2 Total kicks in three treatments and five tests (values are presented as means and 95\% confidence intervals). There was a significant main effect across tests for total kicks. ${ }^{*}=$ significantly lower total kicks compared to tests 1 and $2(P<0.05)$; ${ }^{* *}=$ significantly lower than tests 1,2 , and $3(P<0.05)$ 


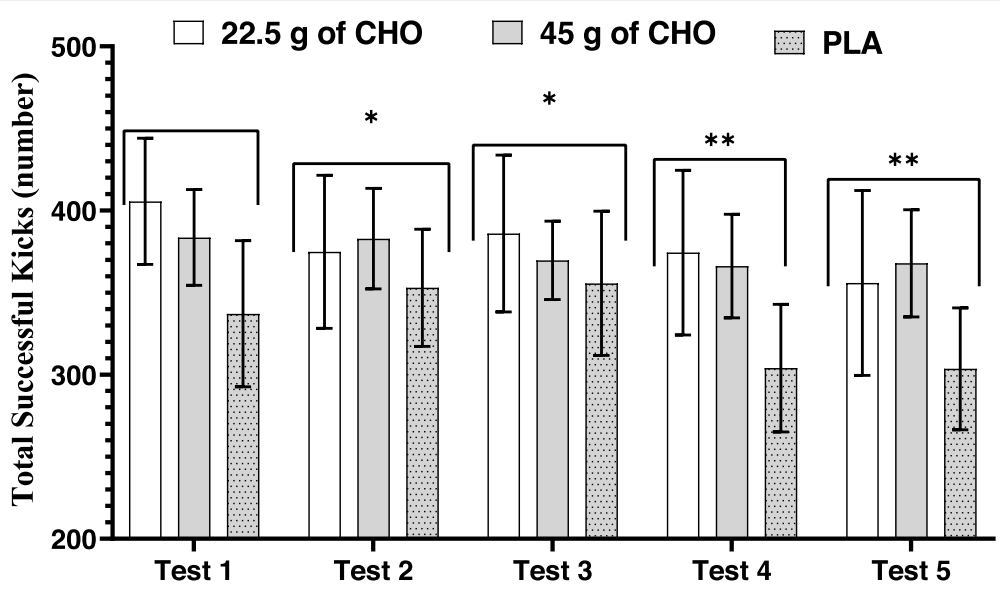

Fig. 3 Total successful kicks in three treatments and five tests (values are presented as means and $95 \%$ confidence intervals). There was a significant main effect across tests for successful kicks. ${ }^{*}=$ significantly lower total kicks compared to test $1(P<0.05) ;{ }^{*}=$ significantly lower than tests 1,2 , and $3(P<0.05)$

nificant $\left(\mathrm{F}_{4,40}=2.575, P=0.052, \eta_{P}^{2}=0.205\right)$ for successful kick percentage (Fig. 4).

\section{Blood glucose}

There was a significant treatment-by-test interaction $\left(\mathrm{F}_{8,80}=2.836, P=0.008, \eta_{P}^{2}=0.221\right)$, for BG. BG increased from test one to four in both $\mathrm{CHO}$ conditions (22.5 and $45 \mathrm{~g}$ of $\mathrm{CHO}$ ) and decreased in test five. Results of further analysis using simple analysis (level of significance was 0.0125), within-subject standard deviation, and 95\% CI are illustrated in Fig. 5.

\section{Rating of perceived exertion}

The treatment-by-test interaction $\left(\mathrm{F}_{8,80}=0.609, \quad P=\right.$ $\left.0.768, \eta_{P}^{2}=0.057\right)$ and main effect of treatment $\left(\mathrm{F}_{2,20}=\right.$
0.643, $\left.P=0.536, \eta_{P}^{2}=0.060\right)$ for RPE were not significant. The main effect of test was significant $\left(\mathrm{F}_{4,40}=\right.$ 4.584, $P=0.004, \eta_{P}^{2}=0.314$ ), and RPE increased from test one to five in all treatments.

\section{Body mass}

The treatment-by-test-by-time interaction $\left(\mathrm{F}_{8,80}=\right.$ 0.459, $\left.P=0.857, \eta_{P}^{2}=0.047\right)$, treatment-by-time interaction $(P=0.108)$, treatment-by-test interaction $(P=$ $0.092)$ and main effect of treatment $(P=0.787)$ for body mass was not significant. However, time-by-test interaction $(P=0.001)$, the main effect of test $(P<$ $0.001)$ and the main effect of time $(P<0.001)$ were significant. Body mass increased from test one to five and decreased from pre-test to post-test in all treatments, but it was not different between treatments.

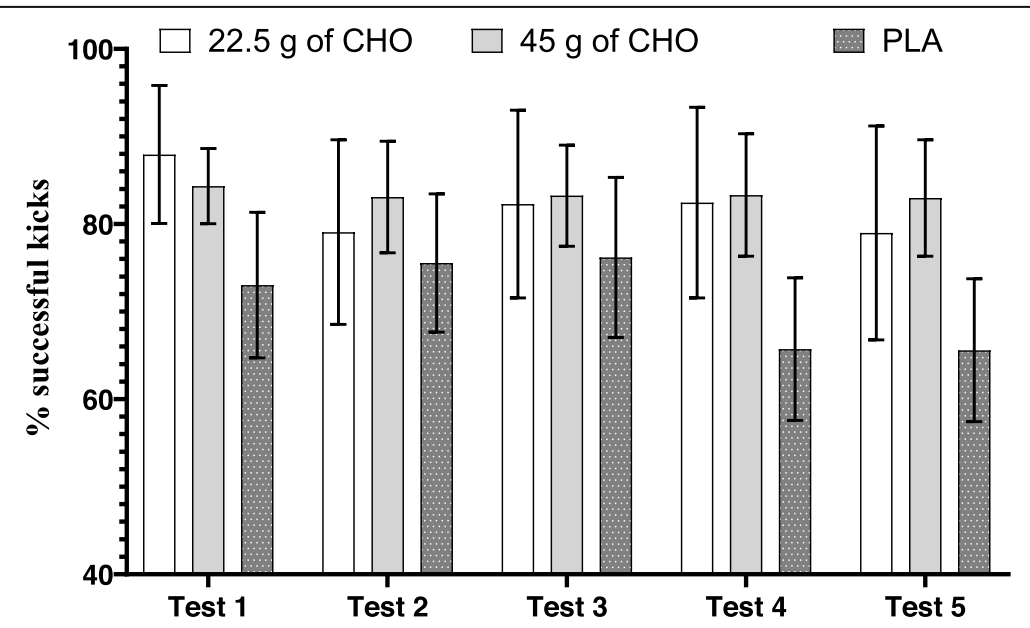

Fig. 4 Successful kick percentage in three treatments and five tests (values are presented as means and 95\% confidence intervals) 


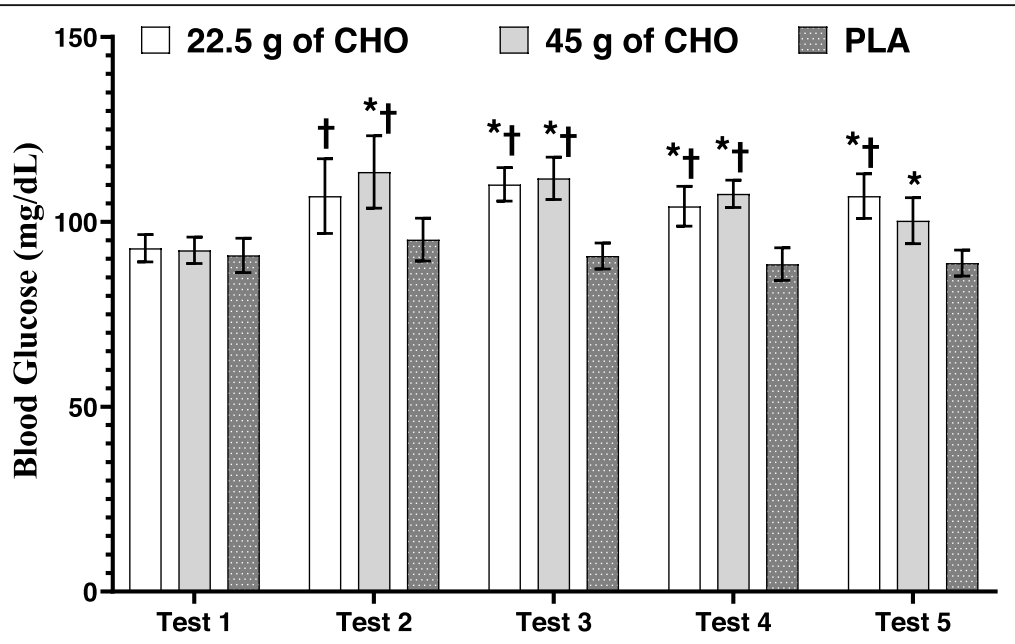

Fig. 5 Blood glucose in three treatments and five tests (values are presented as means and $95 \%$ confidence intervals). ${ }^{*}=$ significantly different than PLA $(P \leq 0.05)$. $\dagger=$ significantly different from test 1 in same treatment $(P \leq 0.05)$

\section{Gastrointestinal symptoms}

Only one participant reported GI discomfort following $45 \mathrm{~g}$ of $\mathrm{CHO}$, reporting very severe reflux/heartburn after tests two and three and a minor one after tests four and five. As well he reported severe belching, bloating, stomach pain/cramps, vomiting, and nausea after test two, and severe stomach pain/cramps after test three.

\section{Discussion}

To our knowledge, this is the first study to investigate the two doses of post-exercise recovery $\mathrm{CHO}$ intake (30 and $60 \mathrm{~g} \cdot \mathrm{h}^{-1}$ ) compared to placebo on repeated sportspecific kicking performance across a simulated taekwondo competition day. In contrast to our hypothesis, $\mathrm{CHO}$ intake, independent of dose, failed to enhance total kicks, total successful kicks, and percentage of successful kicks compared to placebo.

Taekwondo is characterized by repeated bursts of high-intensity activities interspersed with brief rest periods. Oxidative phosphorylation contributes the greatest amount of ATP re-synthesis ( 58-66\%); primarily to support low-intensity actions and rest intervals [2], while non-oxidative energy systems (i.e., $\mathrm{PCr}$ ) and anaerobic glycolysis contribute $\sim 26-30 \%$ and $4-5 \%$, respectively $[2,30]$. Non-oxidative phosphorylation predominantly supports explosive actions, such as kicking, punching, explosive advances, and evasions during a match [30]. Santos et al. reported that a single high-intensity action lasting 1 second was followed by $2-8 \mathrm{~s}$ of step or pause [30]. Further, similar to our taekwondo test, a 1:2 effortpause ratio during a taekwondo youth Olympic match was observed [31]. As such, we modified the Frequency of Speed Kick test with 1:1 effort-pause ratio in taekwondo [25] to more closely simulate the effort-pause of a typical taekwondo match. Additionally, the use of this effort-pause ratio was able to improve Taekwondorelated performance [32].

$\mathrm{CHO}$ storage (i.e. muscle and liver glycogen) and oxidation play an important role during prolonged lowintensity and short duration high-intensity exercise performance [16]. CHO ingestion before and/or during exercise delays peripheral fatigue (i.e., glycogen depletion) and enhances exercise performance [16]. Ingestion of 30-90 g CHO. $\mathrm{h}^{-1}$ in a dose dependent manner enhances exercise capacity, potentially through maintenance of $\mathrm{BG} /$ glycogen and allowing greater $\mathrm{CHO}$ availability and utilization for anaerobic and aerobic glycolysis during exercise $>1 \mathrm{~h}$ [17]. The rate of glycogen depletion during high-intensity exercise also appears to be an important factor associated with metabolic fatigue [33]. As such, $\mathrm{CHO}$ ingestion during acute high intensity exercise has been shown to improve performance. For example, $\mathrm{CHO}$ ingestion enhanced short duration repeated sprints performance [14, 34]. However, these findings were in contrast to our results, possibly suggesting nutrient timing, duration and intensity of exercise, and recovery time intervals may modulate the ergogenic effects of $\mathrm{CHO}$ supplementation.

Taekwondo matches are comprised of intermittent high intensity burst of activity followed by periods of low intensity exercise or rest. During a tournament day these matches are repeated three to five times interspersed with passive rest (ranging from $\sim 30 \mathrm{~min}$ to $3 \mathrm{~h}$ ) [3]. We hypothesized that $\mathrm{CHO}$ ingestion immediately following each sport-specific kicking test would maintain kick performance and euglycemia, across repeated tests. However, in contrast to our hypothesis, there was no statistical differences for percentage of successful kicks, total successful kicks and total kicks across the five tests with either a high $\left(60 \mathrm{~g} \cdot \mathrm{h}^{-1}\right)$ or low dose $\left(30 \mathrm{~g} \cdot \mathrm{h}^{-1}\right)$ of 
CHO compared to PLA. Within combat sports and competition setting, there is limited evidence pertaining to $\mathrm{CHO}$ supplementation and performance and presently it is difficult to compare across studies due to considerable methodological differences, such as different assessments, participant's characteristics, and various types of $\mathrm{CHO}$ and dosages used. Nevertheless, previous research suggests that $\mathrm{CHO}$ ingested during short recovery periods can augment subsequent exercise capacity and glycogen storage in endurance athletes [7, 35]. In this regards, two recent studies reported that subsequent endurance exercise was improved after $1.2 \mathrm{~g} \cdot \mathrm{kg}^{-1} \cdot \mathrm{h}^{-1}$ $\mathrm{CHO}$ was ingested during a $2-4 \mathrm{~h}$ recovery period followed by an intermittent high intensity aerobic test [7] and time to exhaustion at $70 \% \mathrm{VO}_{2} \max$ [35]. In the present study, an absolute dose of $\mathrm{CHO}$ was used for all participants. This dosing strategy was selected due to the relatively short recovery time and the practically of an absolute dose. Furthermore, the kick test and the repetitions of the test were selected to simulate a typical competition day, thus enhancing the external validity. In support of our results, Podlogar et al. 2020 failed to show significant improvements in subsequent exercise performance when either glucose alone or co-ingestion of glucose and fructose were compared to placebo, despite higher $\mathrm{CHO}$ oxidation rates following the ingestion of multiple transportable CHOs [36]. In one of the few studies utilizing taekwondo athletes, no improvements in kick performance with a $\mathrm{CHO}$ mouth rinsing protocol in both fed or fasted states were found [22]. Collectively, despite a likely enhancement of $\mathrm{CHO}$ exogenous and decreasing endogenous $\mathrm{CHO}$ oxidation after two doses of CHO drink [12], it appears that the test used in this study could not possibly results in enough muscle glycogen depletion which may justify the lack of kick performance improvement during five repeated intermittent kick tests with 1:1 effort-pause ratio.

In the present study BG was assessed since hypoglycemia is related to metabolic fatigue during exercise and is associated with impaired performance. Hypoglycemia is defined as a BG lower than $63 \mathrm{mg} \cdot \mathrm{dL}^{-1}\left(3.5 \mathrm{mmol} \cdot \mathrm{L}^{-1}\right)$ [37]. In the current study, both $\mathrm{CHO}$ doses were able to significantly elevate BG assessed after each test (high dose: first test $92.27 \pm 7.5 \mathrm{mg} / \mathrm{dL}$ and last test $100.27 \pm 13 \mathrm{mg} / \mathrm{dL}$; low dose: first test $92.81 \pm 5.5 \mathrm{mg} / \mathrm{dL}$ and last test $106.90 \pm$ $11.08 \mathrm{mg} / \mathrm{dL})$ compared to placebo $(P \leq 0.05)$. However, there was no indication of hypoglycemia in the PLA condition (first test $90.90 \pm 8.1 \mathrm{mg} / \mathrm{dL}$ and last test $88.81 \pm 5.6$ $\mathrm{mg} / \mathrm{dL}$ ). This avoidance of hypoglycemia was likely attributed to the standardized breakfast $\left(1 \mathrm{~g} \cdot \mathrm{kg}^{-1} \mathrm{CHO}\right)$ provided $3 \mathrm{~h}$ prior to the first test, besides the liver glycogenolysis and gluconeogenesis, which may have provided sufficient fuel to maintain the glycaemia during the exercise protocol [38]. Non-glucose substrates required for gluconeogenesis, such as glycerol and lactate are elevated during a simulated taekwondo tournament [39] due to the higher secretion of catecholamines [39] and cortisol [19]. In agreement with our finding, no cases of hypoglycemia were reported (6.1 $6 \pm 0.8-5.6 \pm 1.7 \mathrm{mmol} / \mathrm{L}$ from first to fourth combat) in ten elite taekwondo players during a tournament across 4 matches after consuming a pre-exercise $\mathrm{CHO}$ meal containing 2.7 to $3.7 \mathrm{~g} \cdot \mathrm{kg}^{-1}$ [39].

CHO ingestion did not alter RPE compared to PLA, which is consistent with previous research $[36,40]$. Lastly, a mild to severe GI discomfort adverse event was reported following the high-dose of $\mathrm{CHO}$ ingestion $\left(60 \mathrm{~g} \cdot \mathrm{h}^{-1}\right)$ in one participant. These events are possibly related to the lower rate of gastric emptying following high intensity exercise thorough the splanchnic blood flow decrement (41).

This study also has several limitations. First, the task used in the present study, while taekwondo-specific, did not replicate all the demands and requirements of a real match with an opponent. Further, we only assessed kick performance, which is only one technique among several used in taekwondo. In addition, more research is needed to apply less or more than $45 \mathrm{~min}$ of recovery time between matches, as a match in a real tournament are separated by $30 \mathrm{~min}$ to $3 \mathrm{~h}$. Future research may consider using an accelerometer attached to wireless sensors for measuring speed and force of each kick. Further, we did not assess muscle glycogen or measure $\mathrm{CHO}$ oxidation, which would be of interest in future research. Also, we only used male taekwondo athletes with a relatively low sample size without performing a power analysis. Therefore, future research examining female athletes along with a priori power analysis is required. Lastly, it is worth investigating the effect of $\mathrm{CHO}$ supplementation after acute weight loss during a competition day on combat athletes' performance, which is a situation that muscle glycogen is likely depleted.

In conclusion, $\mathrm{CHO}$ ingestion, independent of dose, failed to enhance kicking performance in a simulated competition day in trained taekwondo athletes.

\section{Abbreviations}

CHO: Carbohydrate; PLA: Placebo; STET: Simulated taekwondo effort test; RPE: Rating perceived exertion; BG: Blood glucose; TAIKT: Anaerobic Intermittent Kick Tests; Cl: Confidence interval

\section{Acknowledgements}

We would like to thank all the participants of this study for participating in this study.

\section{Authors' contributions}

AN conceived the study. AN, EF,RR,EPO designed the study. AN, SR, MS were responsible for coordination the study. AN, SR, MS, HM, EB, MSS and AS collected data. AS analyzed data and reported results. AN, SF, MK, EF, RR and EPO constructed the first manuscript. All authors edited the manuscript and approved the final version of manuscript.

Funding

This study was financially supported by the second author. 


\section{Availability of data and materials}

Data and publication materials are available from the corresponding author on reasonable request.

\section{Declarations}

\section{Ethics approval and consent to participate}

The study was conducted following the Declaration of Helsinki and approved by Islamic Azad University of Boroujerd, Iran. All participants were informed about the procedures and signed an informed consent form prior to commencement of the research.

\section{Consent for publication}

Not applicable.

\section{Competing interests}

The authors declare that they have no competing interests.

\section{Author details}

'Department of Sport Physiology, Boroujerd Branch, Islamic Azad University, Boroujerd, Iran. ${ }^{2}$ Department of Sport Science, Imam Khomeini International University, Qazvin, Iran. ${ }^{3}$ Department of Exercise Physiology, Karaj Branch, Islamic Azad University, Karaj, Iran. ${ }^{4}$ Faculty of Education, Department of Physical Education Studies, Brandon University, Brandon, MB R7A6A9, Canada. ${ }^{5}$ Department of Kinesiology, Jacksonville State University, Jacksonville, AL 36265, USA. ${ }^{6}$ School of Physical Education and Sport, University of São Paulo (USP), São Paulo, Brazil. 'UFC Performance Institute, Shanghai, China. ${ }^{8}$ Department of Exercise Physiology, Faculty of Physical Education and Sport Sciences, Tehran, Iran. ${ }^{9}$ Laboratory of Nutrition, Exercise and Health (LaNES), School of Medicine, Federal University of Uberlandia (UFU), Uberlandia, Minas Gerais, Brazil. ${ }^{10}$ Ebne Sina Sports Medicine Group, Elmi-Karbordi University, Tehran, Iran. ${ }^{11}$ College of Health and Human Sciences, Charles Darwin University, Darwin, Australia.

Received: 25 January 2021 Accepted: 20 April 2021

Published online: 27 May 2021

\section{References}

1. Bridge CA, et al. Physical and physiological profiles of taekwondo athletes. Sports Med. 2014;44(6):713-33.

2. Campos FAD, et al. Energy demands in taekwondo athletes during combat simulation. Eur J Appl Physiol. 2011;112(4):1221-8.

3. Lee $Y$, et al. Immunological impact of taekwondo competitions. Int J Sports Med. 2011;33(01):58-66.

4. Negaresh $R$, et al. Effects of different dosages of caffeine administration on wrestling performance during a simulated tournament. Eur J Sport Sci. 2018;19(4):499-507.

5. Fürnsinn C, et al. Rapid weight reduction does not impair athletic performance of taekwondo athletes - a pilot study. PLoS One. 2018;13(4):e0196568.

6. Gough LA, et al. Post-exercise supplementation of sodium bicarbonate improves Acid Base balance recovery and subsequent high-intensity boxing specific performance. Front Nutr. 2019;6:155.

7. McCarthy DG, Spriet LL. Performance effects of carbohydrate ingestion between bouts of intense aerobic interval exercise. Int I Sports Physiol Performance. 2020;15(2):262-7.

8. Hargreaves M, Spriet LL. Skeletal muscle energy metabolism during exercise. Nat Metab. 2020;2(9):817-28.

9. Rowlands DS, et al. Fructose-glucose composite carbohydrates and endurance performance: critical review and future perspectives. Sports Med. 2015;45(11):1561-76

10. Burke LM, et al. Low carbohydrate, high fat diet impairs exercise economy and negates the performance benefit from intensified training in elite race walkers. J Physiol. 2017;595(9):2785-807.

11. Nybo L. CNS fatigue and prolonged exercise: effect of glucose supplementation. Med Sci Sports Exerc. 2003;35(4):589-94.

12. Trommelen J, et al. Fructose and sucrose intake increase exogenous carbohydrate oxidation during exercise. Nutrients. 2017;9(2):167.

13. Urdampilleta A, et al. Effects of $120 \mathrm{vs} .60$ and $90 \mathrm{~g} / \mathrm{h}$ carbohydrate intake during a trail Marathon on neuromuscular function and high intensity run capacity recovery. Nutrients. 2020;12(7):2094.

14. Pomportes $L$, et al. Effect of carbohydrate intake on maximal power output and cognitive performances. Sports. 2016;4(4):49.
15. Wu C-L, Williams C. A low glycemic index meal before exercise improves endurance running capacity in men. Int J Sport Nutr Exercise Metab. 2006;16(5): $510-27$.

16. Murray B, Rosenbloom C. Fundamentals of glycogen metabolism for coaches and athletes. Nutr Rev. 2018;76(4):243-59.

17. Jeukendrup A. A step towards personalized sports nutrition: carbohydrate intake during exercise. Sports Med. 2014;44(S1):25-33.

18. Jentjens $R$, Jeukendrup AE. Determinants of post-exercise glycogen synthesis during short-term recovery. Sports Med. 2003;33(2):117-44.

19. Chuang S-J, et al. Can match-mimicking intermittent practice be used as a Simulatory training mode of competition using Olympic time frame in elite taekwondo athletes? Front Physiol. 2019;10:244.

20. Sant'Ana J, et al. Effect of fatigue on reaction time, response time, performance time, and kick impact in taekwondo roundhouse kick. Sports Biomechanics. 2016;16(2):201-9.

21. Rockwell MS, Rankin JW, Dixon H. Effects of muscle glycogen on performance of repeated sprints and mechanisms of fatigue. Int I Sport Nutr Exercise Metab. 2003;13(1):1-14.

22. Pak IE, et al. The effect of carbohydrate and caffeine mouth rinsing on kicking performance in competitive taekwondo athletes during Ramadan. J Sports Sci. 2020;38(7):795-800.

23. Goulet EDB. Effect of exercise-induced dehydration on endurance performance: evaluating the impact of exercise protocols on outcomes using a meta-analytic procedure. Br J Sports Med. 2013;47(11):679-86.

24. Pfeiffer $B$, et al. The effect of carbohydrate gels on gastrointestinal tolerance during a 16-km run. Int J Sport Nutr Exercise Metab. 2009:19(5):485-503.

25. da Silva Santos JF, Franchini E. Is frequency speed of kick test responsive to training? A study with taekwondo athletes. Sport Sci Health. 2016;12(3):377-82.

26. Borg GA. Psychophysical bases of perceived exertion. Med Sci Sports Exerc. 1982; 14(5):377-81.

27. Naderi A, et al. Timing, optimal dose and intake duration of dietary supplements with evidence-based use in sports nutrition. J Exerc Nutr Biochem. 2016;20(4):1-12.

28. Cousineau D. Confidence intervals in within-subject designs: a simpler solution to Loftus and Masson's method. Tutor Quant Methods Psychol. 2005;1 (1):42-5.

29. Santos JFdS, Dias Wilson V, Herrera-Valenzuela T, Sander Mansur Machado F. Time-Motion Analysis and Physiological Responses to Taekwondo Combat in Juvenile and Adult Athletes: A Systematic Review. Strength \& Conditioning Journal. 2020;42(2):103-21.

30. Tornello F, et al. Time-motion analysis of youth Olympic taekwondo combats. J Strength Cond Res. 2013;27(1):223-8.

31. Tapia DEA, et al. High-intensity interval training improves specific performance in taekwondo athletes. Revista de Artes Marciales Asiáticas. 2020;15(1):4-13.

32. MacDougall JD, Ward GR, Sutton JR. Muscle glycogen repletion after highintensity intermittent exercise. J Appl Physiol. 1977;42(2):129-32.

33. Krings BM, et al. Effects of carbohydrate ingestion and carbohydrate mouth rinse on repeat Sprint performance. Int J Sport Nutr Exercise Metab. 2017; 27(3):204-12.

34. Maunder ED, Podlogar TMM, Wallis GA. Postexercise fructose-Maltodextrin ingestion enhances subsequent endurance capacity. Med Sci Sports Exerc. 2018:50(5):1039-45.

35. Podlogar T, Wallis GA. Impact of Post-Exercise Fructose-Maltodextrin Ingestion on Subsequent Endurance Performance. Front Nutr. 2020;7:82.

36. Rollo I, et al. Primary, secondary, and tertiary effects of carbohydrate ingestion during exercise. Sports Med. 2020;50(11):1863-71.

37. Marliss EB, et al. Glucose turnover and its regulation during intense exercise and recovery in normal male subjects. Clin Invest Med. 1992;15(5):406-19.

38. Bridge $C A$, et al. Repeated exposure to taekwondo combat modulates the physiological and hormonal responses to subsequent bouts and recovery periods. J Strength Cond Res. 2018;32(9):2529-41.

39. McMahon G, Thornbury A. Ingestion of carbohydrate prior to and during maximal, Sprint interval cycling has no ergogenic effect: a randomized, double-blind, placebo controlled. Crossover study. Nutrients. 2020;12(8):2223.

40. de Oliveira E, Burini R. Carbohydrate-dependent. Exer-Induced Gastroint Distr Nutr. 2014;6(10):4191-9.

\section{Publisher's Note}

Springer Nature remains neutral with regard to jurisdictional claims in published maps and institutional affiliations. 